\title{
The emerging role of miR-506 in cancer
}

\author{
Jian $\mathrm{Li}^{1}$, Jingfang $\mathrm{Ju}^{2}$, Bing $\mathrm{Ni}^{3}$ and Huaizhi Wang ${ }^{1}$ \\ ${ }^{1}$ Institute of Hepatopancreatobiliary Surgery, Southwest Hospital, Third Military Medical University, Chongqing, PR China \\ 2 Translational Research Laboratory, Department of Pathology, Stony Brook University, Stony Brook, NY, USA \\ ${ }^{3}$ Department of Pathophysiology and High Altitude Pathology, Third Military Medical University, Chongqing, PR China \\ Correspondence to: Huaizhi Wang, email: whuaizhi@gmail.com
}

Bing Ni, email: nibingxi@126.com

Jingfang Ju, email: jingfang.ju@stonybrookmedicine.edu

Keywords: microRNAs; miR-506; cancer; tumor suppressor

Received: April 06, $2016 \quad$ Accepted: August 10, 2016

Published: August 15, 2016

\section{ABSTRACT}

MicroRNAs (miRNAs) are small non-coding RNAs that post-transcriptionally regulate gene expression. They are involved in almost all biological processes, and many have been identified as potential oncogenes or tumor suppressor genes. miR506 was recently discovered to play pivotal roles in regulating cell proliferation, differentiation, migration and invasion. Dysregulation of miR-506 has been demonstrated in multiple types of cancers; however, whether it functions as an oncogene or a tumor suppressor seems to be context-dependent. Altered miR-506 expression in cancer is caused by promoter methylation and changes in upstream transcription factors. In this review, we summarize the current understanding of the diverse roles and underlying mechanisms of miR-506 and its involvement in cancer, and suggest the potential therapeutic strategy based on miR-506.

\section{INTRODUCTION}

MicroRNAs (miRNAs) are a class of small ( $\sim 22$ $\mathrm{nt}$ ), non-coding, single-stranded RNAs that regulate gene expression at the post-transcriptional level. miRNAs are generated from endogenously transcribed long primary transcripts (pri-miRNAs), which are further cleaved inside the nucleus by Drosha (RNase III), producing approximately 70-nucleotide stem-loop precursor miRNAs (pre-miRNAs) [1]. Pre-miRNAs are actively transported from the nucleus to the cytoplasm by Exportin 5 and are further processed by Dicer (RNase III) to yield mature miRNAs $[2,3]$. The mature miRNAs are incorporated into RNA-induced silencing complex (RISC) and function as guides that promote binding to complementary sequence in the $3^{\prime}$-untranslated region (3'-UTR) of target genes, thereby triggering mRNA degradation or translational repression $[4,5]$. It is estimated that miRNAs may regulate as much as $30 \%$ of the transcriptome [6]. The discovery of miRNAs has opened up a new field of posttranscriptional regulation of gene expression in organisms. Accumulating evidence suggests that dysregulation of miRNAs is involved in the pathogenesis of many types of human diseases, including cancers [7-9]. miRNAs can act as tumor suppressor genes or oncogenes in a wide range of human malignancies, involving multiple pathways and cellular functions in the development and progression of cancer [10-12].

miR-506 was first identified by Bentwich et al. [13] in the primate testis as a member of an X chromosomelinked miRNA cluster of ten miRNAs, which form a family of related sequences and generate seven distinct seeds (miR-506, miR-507, miR-508, miR-509, miR-510, miR513, and miR-514). The entire miRNA cluster was found to be well conserved among primate species $[14,15]$. Subsequently, Zhao et al. found that miR-506 acts as an anti-oncogenic miRNA in malignantly transformed human bronchial epithelial cells, and restoration of miR-506 in the transformed cells suppressed tumor growth in vitro and in vivo [16]. Another report demonstrated that miR506 prevented TGF- $\beta$-induced epithelial-mesenchymal transition (EMT), augmented E-cadherin expression, and inhibited cell migration and invasion by targeting snail family zinc finger 2 (SNAI2). Decreased miR-506 expression in tumor tissues was significantly correlated with poor prognosis in ovarian cancer patients [17]. Changes in miR-506 expression have been subsequently discovered in other tumor types. However, the expression pattern and roles of miR-506 are complicated, even contradictory, in these reports, suggesting unique roles 
Table 1: Verified direct targets of miR-506

\begin{tabular}{|c|c|c|c|c|c|c|}
\hline GO analysis & $\begin{array}{l}\text { Gene } \\
\text { symbol }\end{array}$ & Description & \begin{tabular}{|l|} 
Target \\
gene \\
expression \\
\end{tabular} & $\begin{array}{l}\text { miR-506 } \\
\text { expression }\end{array}$ & Diseases & References \\
\hline \multirow{5}{*}{$\begin{array}{l}\text { Cell } \\
\text { differentiation }\end{array}$} & $\mathrm{CDH} 2$ & $\begin{array}{l}\text { Cadherin 2, Type 1, N-Cadherin } \\
\text { (Neuronal) }\end{array}$ & $\uparrow$ & $\downarrow$ & EOC & {$[32]$} \\
\hline & STAT3 & $\begin{array}{l}\text { Signal Transducer and Activator } \\
\text { Of Transcription } 3\end{array}$ & $\uparrow$ & $\downarrow$ & $\begin{array}{l}\text { Glioma, } \\
\text { neuroblastoma }\end{array}$ & {$[29,64]$} \\
\hline & Gli3 & GLI Family Zinc Finger 3 & $\uparrow$ & $\downarrow$ & Cervical cancer & {$[33]$} \\
\hline & FLOT1 & Flotillin-1 & $\uparrow$ & $\downarrow$ & \begin{tabular}{|l|}
$\mathrm{ccRCC}$ \\
\end{tabular} & {$[34]$} \\
\hline & IQGAP1 & $\begin{array}{l}\text { IQ motif-containing GTPase } \\
\text { activating protein } 1\end{array}$ & $\uparrow$ & $\downarrow$ & Breast cancer & {$[31]$} \\
\hline \multirow{9}{*}{$\begin{array}{l}\text { Cell adhesion } \\
\text { and migration }\end{array}$} & ITGB1 & Integrin, Beta 1 & $\uparrow$ & $\downarrow$ & Prostate cancer & {$[63]$} \\
\hline & ITGB3 & Integrin, Beta 3 & $\uparrow$ & $\downarrow$ & Prostate cancer & {$[63]$} \\
\hline & ROCK1 & Rho-associated protein kinase 1 & $\uparrow$ & $\downarrow$ & $\mathrm{HCC}$ & {$[25]$} \\
\hline & CD151 & $\begin{array}{l}\text { CD151 Molecule (Raph Blood } \\
\text { Group) }\end{array}$ & $\uparrow$ & $\downarrow$ & Breast cancer & {$[18]$} \\
\hline & SNAI2 & Snail family zinc finger 2 & $\uparrow$ & $\downarrow$ & $\begin{array}{l}\text { Ovarian cancer, } \\
\text { breast cancer, } \\
\text { osteosarcoma }\end{array}$ & {$[17,18,59]$} \\
\hline & VIM & Vimentin & $\uparrow$ & $\downarrow$ & $\begin{array}{l}\text { Ovarian cancer, } \\
\text { Breast cancer }\end{array}$ & {$[18,32]$} \\
\hline & ETS-1 & \begin{tabular}{|l} 
V-Ets Avian Erythroblastosis \\
Virus E26 Oncogene Homolog 1 \\
\end{tabular} & $\uparrow$ & $\downarrow$ & $\mathrm{GC}$ & {$[28]$} \\
\hline & E2H2 & Enhancer of zeste homolog 2 & $\uparrow$ & $\downarrow$ & Colon cancer & {$[37]$} \\
\hline & SPON1 & F-spondin 1 & $\uparrow$ & $\downarrow$ & $\mathrm{HCC}$ & {$[22]$} \\
\hline $\begin{array}{l}\text { Response to } \\
\text { PDGF }\end{array}$ & PDGFRB & $\begin{array}{l}\text { Platelet-derived growth factor } \\
\text { receptor beta }\end{array}$ & $\uparrow$ & $\downarrow$ & Glioblastoma & {$[72]$} \\
\hline \multirow{2}{*}{$\begin{array}{l}\text { Blood vessel } \\
\text { development }\end{array}$} & GATA6 & GATA-binding protein 6 & $\uparrow$ & $\downarrow$ & OSCC & {$[24]$} \\
\hline & SPHK1 & Sphingosine kinase 1 & $\uparrow$ & $\downarrow$ & $\mathrm{HCC}, \mathrm{PC}$ & {$[48,56]$} \\
\hline \multirow{8}{*}{$\begin{array}{l}\text { Cell } \\
\text { proliferation }\end{array}$} & CREB1 & $\begin{array}{ll}\text { cAMP responsive element } \\
\text { binding protein } 1\end{array}$ & $\uparrow$ & $\downarrow$ & $\begin{array}{l}\text { Esophageal } \\
\text { cancer }\end{array}$ & {$[35]$} \\
\hline & PIM3 & $\begin{array}{l}\text { Pim-3 Proto-Oncogene, Serine/ } \\
\text { Threonine Kinase }\end{array}$ & $\uparrow$ & $\downarrow$ & $\mathrm{PC}$ & {$[26]$} \\
\hline & CDK4 & Cyclin-Dependent Kinase 4 & $\uparrow$ & $\downarrow$ & $\begin{array}{l}\text { Ovarian cancer, } \\
\text { neuroblastoma }\end{array}$ & {$[19,64]$} \\
\hline & CDK6 & Cyclin-Dependent Kinase 6 & $\uparrow$ & $\downarrow$ & Ovarian cancer & [19] \\
\hline & N-Ras & $\begin{array}{l}\text { Neuroblastoma RAS Viral } \\
\text { (V-Ras) Oncogene Homolog }\end{array}$ & $\uparrow$ & $\downarrow$ & 16HBE-T & {$[16]$} \\
\hline & YAP & Yes-associated protein & $\uparrow$ & $\downarrow$ & $\begin{array}{l}\mathrm{HCC}, \quad \mathrm{GC}, \\
\text { breast cancer }\end{array}$ & {$[20,23,27]$} \\
\hline & FOXQ1 & Forkhead box Q1 & $\uparrow$ & $\downarrow$ & $\begin{array}{l}\text { NPC, cervical } \\
\text { cancer }\end{array}$ & {$[38,57]$} \\
\hline & $\mathrm{NF}-\kappa \mathrm{B}$ p 65 & $\begin{array}{l}\text { Nuclear Factor Of Kappa Light } \\
\text { Polypeptide Gene Enhancer In } \\
\text { B-Cells P65 }\end{array}$ & $\uparrow$ & $\uparrow$ & Lung cancer & {$[61]$} \\
\hline & & & & & & \\
\hline
\end{tabular}




\begin{tabular}{|l|l|l|l|l|l|l|}
\hline \multirow{4}{*}{$\begin{array}{l}\text { Response } \\
\text { to ionizing } \\
\text { radiation and } \\
\text { drug }\end{array}$} & RAD51 & $\begin{array}{l}\text { RAD51 Recombinase, Double- } \\
\text { strand DNA damage repair gene }\end{array}$ & $\uparrow$ & $\downarrow$ & Ovarian cancer & {$[45]$} \\
\cline { 2 - 7 } & DNMT3B & DNA methyltransferase 3B & $\uparrow$ & $\downarrow$ & CRC & {$[21]$} \\
\hline & DNMT1 & DNA methyltransferase 1 & $\uparrow$ & $\downarrow$ & CRC & {$[21]$} \\
\hline & PPAR $\alpha$ & $\begin{array}{l}\text { Peroxisome proliferator-activated } \\
\text { receptor } \alpha\end{array}$ & $\downarrow$ & $\uparrow$ & Colon cancer & {$[40]$} \\
\hline \multirow{2}{*}{$\begin{array}{l}\text { Cell surface } \\
\text { receptor } \\
\text { signaling } \\
\text { pathway }\end{array}$} & Multidrug resistance protein 4 & $\uparrow$ & $\downarrow$ & HEK293T/17 & {$[73]$} \\
\cline { 2 - 7 } & InsP3R3 & $\begin{array}{l}\text { Insulin-Like Growth Factor 2 } \\
\text { MRNA Binding Protein 1 }\end{array}$ & $\uparrow$ & $\downarrow$ & Glioblastoma & {$[60]$} \\
\cline { 2 - 7 } \\
\cline { 2 - 7 }
\end{tabular}

Abbreviation: EOC: epithelial ovarian cancer; HCC, Hepatocellular carcinoma; PC: pancreatic cancer; ccRCC, Clear cell renal cell carcinoma; OSCC, Oral squamous cell carcinoma; NPC, Nasopharyngeal carcinoma; CRC: colorectal cancer ; 16HBE-T : malignant transformation of human bronchial epithelial cells; HEK293T/17: Human embryonic kidney cells; PBC: Primary Biliary Cirrhosis.

for miR-506 in different tumor types. Mounting evidence has demonstrated that miR-506 is a tumor suppressor gene [16-38] (Figure 1). However, in several cases, miR-506 appears to act as an oncogene $[39,40]$. The purpose of this review is to highlight the emerging and diverse functions of miR-506 and its implication in cancer.

\section{Functions of miR-506 in cancer: evidence from both cultured cell lines and clinical samples}

miRNAs orchestrate their functions primarily by binding to complementary sequences within the 3'-UTR of target mRNAs to diminish translation from these targets. Downregulation or upregulation of miR-506 has been shown to affect diverse biological behaviors by suppressing the translational output of several different target genes. Several miR-506 targets have known roles in various types of cancers (Table 1). Gene ontology (GO, http://www.geneontology.org/) analysis revealed that the targeted genes were related to diverse biological processes. Most of the targeted genes are downregulated in the specific diseases context and are associated with several physiological events including cell proliferation, cell differentiation, cell apoptosis, angiogenesis, cell migration and invasion (Table 1), suggesting the potential roles of miR-506 in normal cellular physiology. However, the exact physiological roles of miR-506 should be revealed in a knockout animal model in the future. In addition, miR506 was also shown to be involved in the pathogenesis of primary biliary cirrhosis via targeting the $\mathrm{Cl}-\mathrm{HCO} 3-$ Anion exchanger 2 mRNA [41] and regulating type III inositol 1,4,5-trisphosphate receptor (InsP3R3)-mediated $\mathrm{Ca} 2+$ signaling and secretion in cholangiocytes [42]. Here, we dissect the functions of miR-506 in different tumor types to highlight its diverse cellular functions.

\section{OVARIAN CANCER}

Recent miRNA expression analyses revealed that a cluster of eight miRNAs, located on chrXq27.3, was down-regulated in patients with early-relapsing ovarian cancer, and miR-506 was among these miRNAs [43]. Ectopic expression of miR-506 inhibited cell proliferation and increased sensitivity to cisplatin in human ovarian cancer cellular models [43]. In another study, Yang et al. showed that miR-506 augmented E-cadherin expression, prevented TGF- $\beta$-induced EMT and inhibited cell migration and invasion by targeting SNAI2 in ovarian cancer [17]. The authors also demonstrated that miR-506 simultaneously suppressed Vimentin and N-cadherin, and silencing of Vimentin reversed EMT and inhibited cell migration and invasion in epithelial ovarian cancer (EOC) cells [32]. Thus, the authors concluded that miR506 downregulation promotes an aggressive phenotype in ovarian carcinoma. In addition, the authors showed that miR-506 expression had an anti-proliferative effect on ovarian cancer cells. Overexpression of miR-506 inhibited proliferation and promoted senescence of ovarian cancer cells via direct targeting CDK4 and CDK6. miR-506 can suppress the CDK4/6-FOXM1 signaling pathway, which is activated in the majority of ovarian carcinomas [19]. Because the acquisition of EMT features has been associated with chemoresistance [44], the researchers also examined the role of miR-506 in chemotherapy response in high-grade ovarian cancers. miR-506 was associated with a better response to therapy and longer progressionfree and overall survival, and miR-506 could augment the response to cisplatin and olaparib via targeting RAD51 to suppress homologous recombination-mediated repair of double-strand breaks in ovarian cancer cell lines [45, 46]. These findings confirm that miR-506 acts as a tumor suppressor in ovarian cancer.

miRNAs have been recognized as important 
prognostic biomarkers in disease management [47]. In the context of ovarian cancer, low levels of miR-506 were significantly associated with poor prognosis in three independent cohorts of ovarian cancer patients [17]. Another study confirmed that high miR-506 expression was positively correlated with early FIGO stage and longer survival in EOC, demonstrating that miR-506 can be used as a prognostic predictor for EOC patients [32]. Although a single miR-506 could be used as prognostic biomarker for ovarian cancer with considerable sensitivity and specificity, considering the innate heterogeneity of ovarian cancer, combination of a panel of relevant miRNAs including miR-506 may have more advantages and future studies are clearly needed to address this issue.

\section{PANCREATIC CANCER}

We recently revealed that the miR-506 promoter is highly methylated in pancreatic cancer (PC) tissues and that reduced miR-506 expression was significantly associated with pathologic tumor status, distant metastasis, clinical stage, and decreased survival of PC patients. miR-506 suppressed cell proliferation, induced cell cycle arrest at the G1/S transition, and enhanced apoptosis and chemosensitivity of PC cells. In addition, we identified sphingosine kinase 1 (SPHK1) as a novel target of miR-

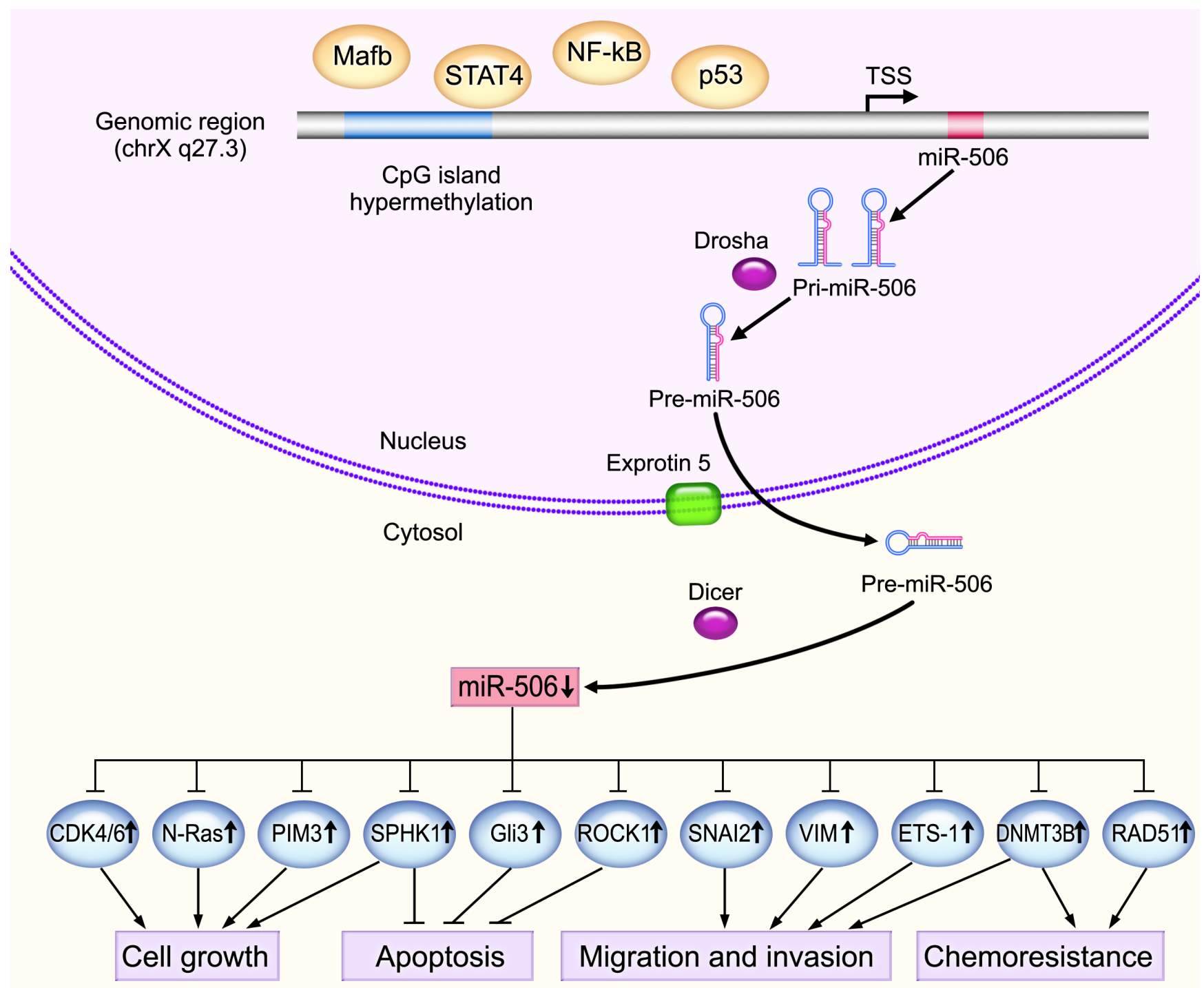

Figure 1: The underlying mechanisms of the tumor suppressive activity of miR-506. Mature miR-506 is processed by RNase III within and outside the nucleus by Drosha and Dicer, respectively. miR-506 is significantly downregulated in various types of cancers and functions as a tumor suppressor by targeting important oncogenes, such as N-Ras, PIM3, SPHK1, ROCK1 and ETS-1, thereby regulating important cancer-related processes, such as cell proliferation, apoptosis, senescence, chemoresistance, invasion and migration. DNA hypermethylation of the $\mathrm{CpG}$ islands in the promoter region of miR-506 blocks miR-506 transcription. In addition, several transcription factors can regulate miR-506 expression. For instance, NF- $\kappa \mathrm{B}$ can bind to the upstream promoter region of miR506 to suppress transcription. 
Table 2: Summary of representative studies investigating the role of miR-506 in clinical samples.

\begin{tabular}{|l|c|c|c|c|}
\hline Cancer types & miR-506 expression & miR-506 function & Prognosis of low miR-506 & References \\
\hline Ovarian cancer & $\downarrow$ & TSG & Poor & {$[17,32,45]$} \\
\hline HCC & $\downarrow$ & TSG & Poor & {$[20,56]$} \\
\hline Breast cancer & $\downarrow$ & TSG & Poor & {$[18]$} \\
\hline Gastric cancer & $\downarrow$ & TSG & Poor & {$[23,28,30]$} \\
\hline Colon cancer & $\downarrow$ & TSG & Poor & {$[37]$} \\
\hline ccRCC & $\downarrow$ & TSG & Poor & {$[48]$} \\
\hline Pancreatic cancer & $\downarrow$ & TSG & UD & {$[33]$} \\
\hline Cervical cancer & $\downarrow$ & TSG & UD & {$[24]$} \\
\hline OSCC & $\downarrow$ & TSG & UD & {$[35]$} \\
\hline Esophageal cancer & $\downarrow$ & TSG & UD & {$[29]$} \\
\hline Glioma & $\downarrow$ & TSG & Poor & {$[38]$} \\
\hline NPC & $\downarrow$ & TSG & UD & {$[61]$} \\
\hline Lung cancer & $\uparrow$ & TSG & Oncogene & {$[39]$} \\
\hline Melanoma & $\uparrow$ & Tlear & & \\
\hline
\end{tabular}

Abbreviation: HCC, Hepatocellular carcinoma; ccRCC, Clear cell renal cell carcinoma; OSCC, Oral squamous cell carcinoma; NPC, Nasopharyngeal carcinoma; TSG, Tumor suppressor gene; UD, undetermined.

506, the expression of which inhibited the SPHK1/Akt/ $\mathrm{NF}-\kappa \mathrm{B}$ signaling pathway, which is activated in PC [48]. Our data suggest that miR-506 acts as a tumor suppressor miRNA and is epigenetically silenced in PC. Consistent with our study, Du et al. also found that the expression of miR-506 was significantly downregulated in PC tissues and negatively correlated with PIM3, a member of the proto-oncogene PIM family [26]. Further studies suggested that miR-506 acts as a tumor suppressor by suppressing PC cell proliferation, which was partially alleviated by PIM3 overexpression. Based on these data, it appears that miR-506 acts as a tumor suppressor in PC. However, as both studies are based on a relative small patient's specimen size, large scales of patient cohorts from multiple centers are needed to confirm the prognostic value of miR-506 in human PC.

\section{GASTRIC CANCER}

To date, a large number of human endogenous miRNAs have been implicated in the pathological tumorigenesis and progression of gastric cancer (GC) [49-51]. Sakimura et al. found that the expression of miR-506 is downregulated in human GC and that low miR-506 expression is significantly associated with poor prognosis, poorly differentiated disease and high SNAI2 expression [30]. Further studies demonstrated that overexpression of miR-506 suppressed GC cell proliferation and migration via downregulating SNAI2, a transcriptional repressor of E-cadherin [30]. Deng et al. also demonstrated that miR-506 expression is decreased in GC patients and that low miR-506 expression is associated with tumor size, pathological tumor node metastasis stage, and lymph node metastases [23]. Ectopic expression of
miR-506 inhibited cell proliferation, invasion, and EMT in GC cells by directly targeting Yes-associated protein 1 (YAP1). Meanwhile, reintroduction of Yap1 rescued the miR-506-induced effects on cell proliferation and invasion [23]. Another report confirmed that miR-506 is downregulated in metastatic gastric cancer cell lines and that low expression of miR-506 is associated with poor overall GC patient survival [28]. Further study suggested that miR-506 overexpression in GC inhibited endothelial cell angiogenesis and metastatic invasion via suppressing the proto-oncogene transcription factor ETS-1 [28], which plays an important role in angiogenesis and tumor metastasis [52]. Therefore, miR-506 functions as a tumor suppressor and has potential value for GC prognosis.

\section{BREAST CANCER}

Many miRNAs, including miR-506, have demonstrated roles in the pathophysiology of breast cancer [53-55]. Arora et al. found that miR-506, predicted to target EMT-related genes, is significantly related to breast cancer patient survival [18]. Overexpression of miR-506 suppressed TGF- $\beta$-induced EMT and inhibited adhesion, invasion, and migration via downregulating mesenchymal genes such as SNAI2, Vimentin, and CD151. Further study suggested that NF- $\kappa \mathrm{B}$ bound to the upstream promoter region of miR-506 to suppress transcription of the miRNA [18]. Yu et al. demonstrated that overexpression of miR-506 significantly suppressed the proliferation, colony formation, and migration of breast cancer cells [36]. Another study demonstrated that miR-506 was downregulated in human breast cancer tissues and cell lines and that the expression level of miR506 was reduced with increasing tumor stage [31]. Gain- 
of-function and loss-of-function experiments revealed that overexpression of miR-506 inhibited cell proliferation, adhesion and invasion by directly targeting the IQ motifcontaining GTPase activating protein 1 (IQGAP1) and repressing the downstream extracellular signal regulated kinase (ERK) mitogen-activated protein kinase (MAPK) signaling pathways. In addition, IQGAP1 rescued the suppressive effect of miR-506 on cell proliferation, adhesion, invasion, and the activation of ERK/MAPK signaling [31]. Hua et al. confirmed that miR-506 was commonly downregulated in breast cancer and that miR-506 suppressed cellular proliferation, migration and invasion by directly binding to the 3 '-UTR of YAP mRNA [27]. These reports provide evidence that miR506 is frequently downregulated in breast cancer and acts as a tumor suppressor gene. Nevertheless, there are still limited studies to investigate the potential role of miR506 as biomarker for diagnosis and/or follow-up of breast cancer, which has to be clarified in the future.

\section{HEPATOCELLULAR CARCINOMA}

Wang et al. demonstrated that the expression of miR506 was significantly lower in hepatocellular carcinoma (HCC) tissues and negatively correlated with YAP [20]. A further study suggested that miR-506 significantly inhibited the proliferation of HepG2 and H7402 cells via targeting YAP and repressing the YAP-targeting genes c-Myc and connective tissue growth factor (CTGF). In another study, the expression level of miR-506 was negatively correlated with SPHK1 in HCC, and miR-506 suppressed angiogenesis in HCC by targeting SPHK1 [56]. This is the first reported study that highlighted the pivotal role of miR-506 in tumor angiogenesis, basing on human umbilical vein endothelial cell (HUVEC) tube formation assay in vitro. However, miR-506 knockdown or knockout animal models is warranted to elucidate the exact roles of miR-506 on tumor angiogenesis in the future. Deng et al. also found that miR-506 significantly inhibited HCC cell proliferation in vitro and tumorigenicity in vivo and identified Rho-associated protein kinase 1(ROCK1) as a novel target of miR-506 [25]. Dai et al. confirmed that miR-506 is downregulated in HCC and inhibits proliferation, migration and invasion by suppressing F-spondin 1 (SPON1). Restoring SPON1expression and silencing of SPON1 in vitro reversed the effects of miR506 mimics and inhibitors, respectively [22]. Therefore, all these findings highlight the tumor suppressive roles of miR-506 in HCC.

\section{COLORECTAL CANCER}

Zhang et al. reported that miR-506 was downregulated in colon cancer cell lines and tumor tissues, and miR-506 expression was inversely correlated with tumor size, lymph node invasion, TNM stage, and metastasis. Furthermore, low levels of miR-506 were associated with poor prognosis [37]. miR-506 inhibited the proliferation and metastasis of colon cancer via binding to the 3'-UTR of enhancer of zeste homolog 2 (EZH2), a member of the Polycomb group (PcG) protein family. Restoration of EZH2 expression partially alleviated the effects of miR-506-overexpressing colon cancer cells. Moreover, the miR-506-EZH2 axis suppressed proliferation and metastasis by activating/inhibiting specific downstream tumor-associated genes and the $\mathrm{Wnt} / \beta$-catenin signaling pathway [37]. In another study, Chen et al. elucidated that miR-506 and miR-124 levels were significantly reduced in human colorectal cancer (CRC) tissues and that miR-506 and miR-124 inhibited progression and enhanced sensitivity to chemotherapy by downregulating DNMT3B and DNMT1 in CRC [21]. In addition, Tong et al. reported that miR-506 was overexpressed in hydroxycamptothecin (HCPT)-resistant human colon cancer cells and that miR-506 conferred HCPT resistance by targeting PPAR $\alpha$ [40]. These studies suggest that miR-506 could either inhibit or enhance chemoresistance of CRC cells in a cell-type-dependent manner. Further clinical investigation and animal experiment are needed to dissect the paradoxical functions of miR-506 in different genetic context.

\section{OTHER TUMOR TYPES}

In addition to the aforementioned tumors, the tumor suppressive role of miR-506 has been widely investigated in many other malignancies, including esophageal cancer [35], glioma [29], oral squamous cell carcinoma [24], cervical cancer $[33,57]$, clear cell renal cell carcinoma $[34,58]$, nasopharyngeal carcinoma [38], osteosarcoma [59], glioblastoma [60], and lung cancer [61] (Table 2). Moreover, other studies have investigated the potential roles of miR-506 in cancer. Through subpathway analysis of each subtype of head and neck squamous cell carcinoma (HNSCC), An et al. demonstrated that several miRNAs (miR-506, let-7a, miR-1, miR-206, miR-153, and miR-519a) and their target genes play crucial roles in the prevention of HNSCC via regulating several distinct pathways [62]. Li et al. reported that miR-506 was the most significant miRNA screened by a bioinformatics strategy in prostate cancer and was found to regulate genes including ITGB1 and ITGB3 by binding the target sequence GUGCCUU [63]. Therefore, miR506 might play an important role in the pathogenesis of prostate cancer [63]. Using a high-content morphological screen to identify differentiation-inducing miRNAs in neuroblastoma, Zhao et al. found that the most potent inducer of differentiation was the miR-506-3p/miR-124$3 p$ seed family and that miR-506-3p expression but not miR-124-3p is dramatically upregulated in differentiated neuroblastoma cells, indicating an important role for endogenous miR-506-3p in differentiation and 
tumorigenesis [64]. Additional investigations are certainly warranted to fully characterize the function of miR-506 in these cancers.

Despite the well characterized role of miR-506 as a tumor suppressor, emerging evidence indicates that miR-506 functions as an oncogene in melanoma and confers chemoresistance in colon cancer. Streicher et al. reported that miR-506, a member of the miR-506-514 cluster, was consistently overexpressed in almost all melanoma samples and suggested it had an oncogenic role, initiating melanocyte transformation and promoting melanoma growth [39]. Clearly, melanoma is a cancer that is quite different and unique from other tumor types and it response well to immunotherapy while other solid tumor types do not. DNA sequence analysis revealed that the upstream of the miR-506-514 cluster did not have strong binding sites for transcription factors relevant to cancer, indicating a novel mechanism for upregulation of the miRNA cluster [39]. The gene expression changes caused during melanocyte transformation might provide a clue. However, the miR-506-514 cluster is upstream of several pathways involved in tumor development and progression, further work will be needed to understand whether expression of this cluster is regulated by transcription factors correlated with these pathways [39]. In addition, using miRNA microarray analyses, Tong et al. demonstrated that miR-506 was overexpressed in hydroxycamptothecin (HCPT)-resistant human colon cancer cells and that miR-506 conferred cancer cells resistance to HCPT by inhibiting PPAR $\alpha$ expression [40].

\section{REGULATION OF MIR-506 EXPRESSION}

Similar to protein-encoding genes, different regulatory mechanisms can control miRNA expression at a genetic or epigenetic level, and miRNA expression can also be affected by the dysregulation of specific transcription factors [65]. Recent studies have demonstrated that epigenetic inactivation is a common method of silencing miRNAs [66, 67]. Yang et al. identified five $\mathrm{CpG}$ sites in the promoter region of the miR-506 gene in ovarian cancer. Using quantitative pyrosequencing following sodium bisulfite treatment of DNA isolated from ovarian cancer tissues, the authors demonstrated that two of the five methylation sites exhibited trends of negative correlation between methylation and miR-506 expression. Treating the ovarian cancer cell line SKOV3 with 5-aza-2'-deoxycytidine (5-Aza-dC), a demethylating agent, significantly restored miR-506 levels [17]. Our group compared miR-506 promoter methylation levels between PC tissues, adjacent non-cancerous tissues and normal pancreatic tissues and found that DNA hypermethylation may account for the downregulation of miR-506 in PC. Treating PC cell lines with 5-Aza-dC resulted in a significant upregulation of miR-506 [48]. Meanwhile, Arora et al. revealed a putative
$\mathrm{NF}-\kappa \mathrm{B}$ binding site at $-1013 \mathrm{bp}$ from precursor miR506 through promoter sequence analysis. The authors confirmed that NF- $\kappa \mathrm{B}$ bound to the upstream promoter region of the miR-506 gene to suppress transcription by chromatin immunoprecipitation (ChIP) assays, and miR506 expression was induced by the suppression of NF- $\mathrm{NB}$ in breast cancer cell lines [18]. In addition, Zhao et al. demonstrated that transcription factors Mafb and STAT4 negatively regulate $\mathrm{miR}-506$, indicating another regulatory network that could regulate miR-506 expression [68]. With respect to the upregulation of miR-506, Yin et al. found a putative p53-response element approximately 782 bp upstream of miR-506, and qPCR results revealed a significant correlation between miR-506 and p53 mRNAs levels in stage I lung cancer patients. miR-506 was markedly induced by the adriamycin treatment in lung cancer cell lines that express functional p53 [61] (Figure $1)$.

\section{THERAPEUTIC POTENTIAL OF MIR-506}

Based on the critical roles of miRNAs in cancer, miRNAs exhibit great potential as novel therapeutic agents. A growing body of evidence has revealed that miR-506 is one of the most significantly downregulated miRNAs in various types of cancer and plays important tumor suppressive roles in vitro and in vivo [22, 33, 37]. Yang et al. reported that delivery of miR-506 incorporated in DOPC nanoliposomes in orthotopic ovarian cancer mouse models inhibited tumor growth and led to E-cadherin expression [17]. In another study, systemic delivery of miR-506 significantly enhanced the effect of cisplatin and olaparib in orthotopic ovarian cancer models [45]. Our previous study demonstrated that lentivirusmediated miR-506 overexpression could inhibit PI3K/ Akt signaling, impair the viability of PC cells, and slow the growth of PC xenografts in mice [48]. Moreover, miR-506 has been shown to inhibit the proliferation and tumorigenicity of several types of cancer cells [22, 25, $29,33,37]$ and suppress migration in vitro and in vivo $[21,37]$. Thus, these results provide a strong rationale for utilizing miR-506 analogues to treat cancer in the future. However, we must bear in mind that the function of miR506 is cell-specific, and a thorough understanding of its diverse functions is crucial for developing miR-506-based therapies. With miR-34 currently in a Phase I clinical trials as the first miRNA mimic for cancer treatment, all eyes are on the progress of miRNA-based therapeutics [69]. Although many hurdles may lie ahead, such as the low stability of synthetic RNA in vivo, effective delivery of miRNA and retention of miRNAs [70, 71], we are optimistic about the future of miRNA-based cancer therapeutics. 


\section{CONCLUSIONS AND PERSPECTIVES}

Most of the reported studies clearly demonstrated that miR-506 is commonly downregulated and acts primarily as a tumor suppressor in various cancers (Table 2). Evidence from both clinical samples and cancer cell lines suggest that dysregulation of miR-506 plays crucial roles in cancer development. However, considering the limited numbers of studies available and the bidirectional and context-specific roles of miR-506 (e.g., in melanoma), more investigations are warranted because melanoma is a unique disease in several aspects. The following molecular and cellular mechanistic questions may deserve future investigations. The normal physiologic role of miR-506 needs to be fully elucidated in a knockout or knockdown animal model. Secondly, the upstream molecular regulators of miR-506, which are responsible for aberrant expression of miR-506, such as NF- $\mathrm{BB}$ [18], p53 [61], Mafb and STAT4 [68], need to be explored. Additional targets of miR-506 need to be identified to reveal additional pathways to TGF- $\beta$ [17], Akt [48], NF- $\mathrm{BB}$ [61], Wnt/ $\beta$-catenin [37], STAT3 [29], Gli3 [33], and FOXM1 [19] that are regulated by miR-506. These studies would help us to better understand the pleiotropic functions of miR-506 in cancer development. Last, additional studies are clearly needed to fully validate the usefulness of miR506 as a diagnostic and/or prognostic biomarker.

\section{CONFLICTS OF INTEREST}

The authors declare that they have no conflict of interest.

\section{FUNDING}

This work was supported by the following grants: the National Natural Science Foundation of China (No. 81372242); the National High Technology Research and Development Program of China (Program 863) (No. 2012AA021105); the Research Special Fund for Public Welfare Industry of Health (No. 201202007); the Clinical Research Foundation of TMMU (No. SWH2015LC01); and the Youth Innovation Foundation of TMMU (No. SWH2015QN01).

\section{REFERENCES}

1. Lee Y, Ahn C, Han J, Choi H, Kim J, Yim J, Lee J, Provost P, Radmark O, Kim S and Kim VN. The nuclear RNase III Drosha initiates microRNA processing. Nature. 2003; 425(6956):415-419.

2. Yi R, Qin Y, Macara IG and Cullen BR. Exportin-5 mediates the nuclear export of pre-microRNAs and short hairpin RNAs. Genes \& development. 2003; 17(24):30113016.
3. Chendrimada TP, Gregory RI, Kumaraswamy E, Norman J, Cooch N, Nishikura K and Shiekhattar R. TRBP recruits the Dicer complex to Ago 2 for microRNA processing and gene silencing. Nature. 2005; 436(7051):740-744.

4. Bartel DP. MicroRNAs: target recognition and regulatory functions. Cell. 2009; 136(2):215-233.

5. Gregory RI, Chendrimada TP, Cooch N and Shiekhattar R. Human RISC couples microRNA biogenesis and posttranscriptional gene silencing. Cell. 2005; 123(4):631640.

6. Lewis BP, Burge CB and Bartel DP. Conserved seed pairing, often flanked by adenosines, indicates that thousands of human genes are microRNA targets. Cell. 2005; 120(1):15-20.

7. Jamieson NB, Morran DC, Morton JP, Ali A, Dickson EJ, Carter CR, Sansom OJ, Evans TRJ, McKay CJ and Oien KA. MicroRNA molecular profiles associated with diagnosis, clinicopathologic criteria, and overall survival in patients with resectable pancreatic ductal adenocarcinoma. Clin Cancer Res. 2012; 18(2):534-545.

8. Mendell JT and Olson EN. MicroRNAs in stress signaling and human disease. Cell. 2012; 148(6):1172-1187.

9. Lin S and Gregory RI. MicroRNA biogenesis pathways in cancer. Nature reviews Cancer. 2015; 15(6):321-333.

10. Chen CZ. MicroRNAs as oncogenes and tumor suppressors. The New England journal of medicine. 2005; 353(17):17681771.

11. Ma L, Teruya-Feldstein $\mathrm{J}$ and Weinberg RA. Tumour invasion and metastasis initiated by microRNA-10b in breast cancer. Nature. 2007; 449(7163):682-688.

12. Kong KL, Kwong DL, Chan TH, Law SY, Chen L, Li Y, Qin YR and Guan XY. MicroRNA-375 inhibits tumour growth and metastasis in oesophageal squamous cell carcinoma through repressing insulin-like growth factor 1 receptor. Gut. 2012; 61(1):33-42.

13. Bentwich I, Avniel A, Karov Y, Aharonov R, Gilad S, Barad O, Barzilai A, Einat P, Einav U, Meiri E, Sharon E, Spector Y and Bentwich Z. Identification of hundreds of conserved and nonconserved human microRNAs. Nat Genet. 2005; 37(7):766-770.

14. Zhang R, Peng Y, Wang W and Su B. Rapid evolution of an X-linked microRNA cluster in primates. Genome Res. 2007; 17(5):612-617.

15. Li JJ, Liu Y, Dong D and Zhang ZL. Evolution of an X-Linked Primate-Specific Micro RNA Cluster. Mol Biol Evol. 2010; 27(3):671-683.

16. Zhao Y, Liu H, Li Y, Wu J, Greenlee AR, Yang C and Jiang Y. The role of miR-506 in transformed 16HBE cells induced by anti-benzo [a]pyrene-trans-7,8-dihydrodiol9,10-epoxide. Toxicol Lett. 2011; 205(3):320-326.

17. Yang D, Sun Y, Hu L, Zheng H, Ji P, Pecot CV, Zhao Y, Reynolds S, Cheng H, Rupaimoole R, Cogdell D, Nykter M, Broaddus R, Rodriguez-Aguayo C, Lopez-Berestein $\mathrm{G}$, Liu J, et al. Integrated Analyses Identify a Master 
MicroRNA Regulatory Network for the Mesenchymal Subtype in Serous Ovarian Cancer. Cancer Cell. 2013; 23(2):186-199.

18. Arora H, Qureshi R and Park WY. miR-506 regulates epithelial mesenchymal transition in breast cancer cell lines. PLoS One. 2013; 8(5):e6273.

19. Liu G, Sun Y, Ji P, Li X, Cogdell D, Yang D, Parker Kerrigan BC, Shmulevich I, Chen K, Sood AK, Xue F and Zhang W. MiR-506 suppresses proliferation and induces senescence by directly targeting the CDK4/6-FOXM1 axis in ovarian cancer. The Journal of pathology. 2014; 233(3):308-318.

20. Wang Y, Cui M, Sun BD, Liu FB, Zhang XD and Ye LH. MiR-506 suppresses proliferation of hepatoma cells through targeting YAP mRNA 3'UTR. Acta Pharmacol Sin. 2014; 35(9):1207-1214.

21. Chen Z, Liu S, Tian L, Wu M, Ai F, Tang W, Zhao L, Ding J, Zhang L and Tang A. miR-124 and miR-506 inhibit colorectal cancer progression by targeting DNMT3B and DNMT1. Oncotarget. 2015; 6(35):38139-38150. doi: 10.18632/oncotarget.5709.

22. Dai W, Huang HL, Hu M, Wang SJ, He HJ, Chen NP and Li MY. microRNA-506 regulates proliferation, migration and invasion in hepatocellular carcinoma by targeting F-spondin 1 (SPON1). American journal of cancer research. 2015; 5(9):2697-2707.

23. Deng J, Lei W, Xiang X, Zhang L, Yu F, Chen J, Feng $\mathrm{M}$ and Xiong J. MicroRNA-506 inhibits gastric cancer proliferation and invasion by directly targeting Yap1. Tumour biology. 2015; 36(9):6823-6831.

24. Deng L and Liu H. MicroRNA-506 suppresses growth and metastasis of oral squamous cell carcinoma via targeting GATA6. International journal of clinical and experimental medicine. 2015; 8(2):1862-1870.

25. Deng Q, Xie L and Li H. MiR-506 suppresses cell proliferation and tumor growth by targeting Rho-associated protein kinase 1 in hepatocellular carcinoma. Biochemical and biophysical research communications. 2015; 467(4):921-927.

26. Du JD, Zheng X, Cai SW, Zhu ZM, Tan JW, Hu B, Huang ZQ and Jiao HB. MicroRNA-506 participates in pancreatic cancer pathogenesis by targeting PIM3. Mol Med Rep. 2015; 12(4):5121-5126.

27. Hua K, Yang W, Song H, Song J, Wei C, Li D and Fang L. Up-regulation of miR-506 inhibits cell growth and disrupt the cell cycle by targeting YAP in breast cancer cells. International journal of clinical and experimental medicine. 2015; 8(8):12018-12027.

28. Li Z, Liu Z, Dong S, Zhang J, Tan J, Wang Y, Ge C, Li R, Xue Y, Li M, Wang W, Xiang X, Yang J, Ding H, Geng T, Yao K, et al. miR-506 Inhibits Epithelial-to-Mesenchymal Transition and Angiogenesis in Gastric Cancer. The American journal of pathology. 2015; 185(9):2412-2420.

29. Peng T, Zhou L, Zuo L and Luan Y. miR-506 functions as a tumor suppressor in glioma by targeting STAT3. Oncology reports. 2015; 35(2):1057-1064.

30. Sakimura S, Sugimachi K, Kurashige J, Ueda M, Hirata H, Nambara S, Komatsu H, Saito T, Takano Y, Uchi R, Sakimura E, Shinden Y, Iguchi T, Eguchi H, Oba Y, Hoka $\mathrm{S}$, et al. The miR-506-induced epithelial-mesenchymal transition is involved in poor prognosis for patients with gastric cancer. Annals of surgical oncology. 2015; 22(Suppl 3):1436-1443.

31. Sun G, Liu Y, Wang K and Xu Z. miR-506 regulates breast cancer cell metastasis by targeting IQGAP1. International journal of oncology. 2015; 47(5):1963-1970.

32. Sun Y, Hu L, Zheng H, Bagnoli M, Guo Y, Rupaimoole R, Rodriguez-Aguayo C, Lopez-Berestein G, Ji P, Chen K, Sood AK, Mezzanzanica D, Liu J, Sun B and Zhang W. MiR-506 inhibits multiple targets in the epithelial-tomesenchymal transition network and is associated with good prognosis in epithelial ovarian cancer. The Journal of pathology. 2015; 235(1):25-36.

33. Wen SY, Lin Y, Yu YQ, Cao SJ, Zhang R, Yang XM, Li J, Zhang YL, Wang YH, Ma MZ, Sun WW, Lou XL, Wang JH, Teng YC and Zhang ZG. miR-506 acts as a tumor suppressor by directly targeting the hedgehog pathway transcription factor Gli3 in human cervical cancer. Oncogene. 2015; 34(6): 717-725.

34. Yang FQ, Zhang HM, Chen SJ, Yan Y and Zheng JH. MiR506 is down-regulated in clear cell renal cell carcinoma and inhibits cell growth and metastasis via targeting FLOT1. PloS one. 2015; 10(3):e0120258.

35. Yao WJ, Wang YL, Lu JG, Guo L, Qi B and Chen ZJ. MicroRNA-506 inhibits esophageal cancer cell proliferation via targeting CREB1. International journal of clinical and experimental pathology. 2015; 8(9):10868-10874.

36. Yu F, Lv M, Li D, Cai H, Ma L, Luo Q, Yuan X and Lv Z. MiR-506 Over-Expression Inhibits Proliferation and Metastasis of Breast Cancer Cells. Medical science monitor. 2015; 21:1687-1692.

37. Zhang Y, Lin C, Liao G, Liu S, Ding J, Tang F, Wang Z, Liang X, Li B, Wei Y, Huang Q, Li X and Tang B. MicroRNA-506 suppresses tumor proliferation and metastasis in colon cancer by directly targeting the oncogene EZH2. Oncotarget. 2015; 6(32):32586-32601. doi: 10.18632/oncotarget.5309.

38. Zhang Z, Ma J, Luan G, Kang L, Su Y, He Y and Luan F. MiR-506 suppresses tumor proliferation and invasion by targeting FOXQ1 in nasopharyngeal carcinoma. PloS one. 2015; 10(4):e0122851.

39. Streicher KL, Zhu W, Lehmann KP, Georgantas RW, Morehouse CA, Brohawn P, Carrasco RA, Xiao Z, Tice DA, Higgs BW, Richman L, Jallal B, Ranade K and Yao Y. A novel oncogenic role for the miRNA-506-514 cluster in initiating melanocyte transformation and promoting melanoma growth. Oncogene. 2012; 31(12):1558-1570.

40. Tong JL, Zhang CP, Nie F, Xu XT, Zhu MM, Xiao SD 
and Ran ZH. MicroRNA 506 regulates expression of PPAR alpha in hydroxycamptothecin- resistant human colon cancer cells. FEBS Lett. 2011; 585(22):3560-3568.

41. Banales JM, Saez E, Uriz M, Sarvide S, Urribarri AD, Splinter P, Tietz Bogert PS, Bujanda L, Prieto J, Medina JF and Larusso NF. Up-regulation of microRNA 506 leads to decreased $\mathrm{Cl}-\mathrm{HCO} 3$ - anion exchanger 2 expression in biliary epithelium of patients with primary biliary cirrhosis. Hepatology. 2012; 56(2):687-697.

42. Ananthanarayanan M, Banales JM, Guerra MT, Spirli C, Munoz-Garrido P, Mitchell-Richards K, Tafur D, Saez E and Nathanson MH. Post-translational regulation of the type III inositol 1,4,5-trisphosphate receptor by miRNA-506. The Journal of biological chemistry. 2015; 290(1):184-196.

43. Bagnoli M, De Cecco L, Granata A, Nicoletti R, Marchesi E, Alberti P, Valeri B, Libra M, Barbareschi M, Raspagliesi F, Mezzanzanica D and Canevari S. Identification of a chrXq27.3 microRNA cluster associated with early relapse in advanced stage ovarian cancer patients. Oncotarget. 2011; 2(12):1265-1278. doi: 10.18632/oncotarget.401.

44. Iwatsuki M, Mimori K, Yokobori T, Ishi H, Beppu T, Nakamori S, Baba H and Mori M. Epithelial-mesenchymal transition in cancer development and its clinical significance. Cancer science. 2010; 101(2):293-299.

45. Liu G, Yang D, Rupaimoole R, Pecot CV, Sun Y, Mangala LS, Li X, Ji P, Cogdell D, Hu L, Wang Y, RodriguezAguayo C, Lopez-Berestein G, Shmulevich I, De Cecco L, Chen K, et al. Augmentation of response to chemotherapy by microRNA-506 through regulation of RAD51 in serous ovarian cancers. Journal of the National Cancer Institute. 2015; 107(7):pii: djv108.

46. Liu G, Xue F and Zhang W. miR-506: a regulator of chemosensitivity through suppression of the RAD51-homologous recombination axis. Chinese journal of cancer. 2015; 34(3):44.

47. Shen J, Stass SA and Jiang F. MicroRNAs as potential biomarkers in human solid tumors. Cancer letters. 2013; 329(2):125-136.

48. Li J, Wu H, Li W, Yin L, Guo S, Xu X, Ouyang Y, Zhao Z, Liu S, Tian Y, Tian Z, Ju J, Ni B and Wang H. Downregulated miR-506 expression facilitates pancreatic cancer progression and chemoresistance via SPHK1/Akt/ NF-kappaB signaling. Oncogene. 2016.

49. Li Z, Yu X, Wang Y, Shen J, Wu WK, Liang J and Feng F. By downregulating TIAM1 expression, microRNA-329 suppresses gastric cancer invasion and growth. Oncotarget. 2015; 6(19):17559-17569. doi: 10.18632/oncotarget. 2755 .

50. Yanaka Y, Muramatsu T, Uetake H, Kozaki K and Inazawa J. miR-544a induces epithelial-mesenchymal transition through the activation of WNT signaling pathway in gastric cancer. Carcinogenesis. 2015; 36(11):1363-1371.

51. Li BS, Zuo QF, Zhao YL, Xiao B, Zhuang Y, Mao $\mathrm{XH}, \mathrm{Wu} \mathrm{C}$, Yang SM, Zeng H, Zou QM and Guo G. MicroRNA-25 promotes gastric cancer migration, invasion and proliferation by directly targeting transducer of ERBB2, 1 and correlates with poor survival. Oncogene. 2015; 34(20):2556-2565.

52. Lin Z, Liu Y, Sun Y and He X. Expression of Ets-1, Ang2 and maspin in ovarian cancer and their role in tumor angiogenesis. Journal of experimental \& clinical cancer research. 2011; 30:31.

53. Serpico D, Molino L and Di Cosimo S. microRNAs in breast cancer development and treatment. Cancer treatment reviews. 2014; 40(5):595-604.

54. Ward A, Balwierz A, Zhang JD, Kublbeck M, Pawitan Y, Hielscher T, Wiemann S and Sahin O. Re-expression of microRNA-375 reverses both tamoxifen resistance and accompanying EMT-like properties in breast cancer. Oncogene. 2013; 32(9):1173-1182.

55. Bockhorn J, Dalton R, Nwachukwu C, Huang S, Prat A, Yee K, Chang YF, Huo D, Wen Y, Swanson KE, Qiu T, Lu J, Park SY, Dolan ME, Perou CM, Olopade OI, et al. MicroRNA-30c inhibits human breast tumour chemotherapy resistance by regulating TWF1 and IL-11. Nature communications. 2013; 4:1393.

56. Lu Z, Zhang W, Gao S, Jiang Q, Xiao Z, Ye L and Zhang X. MiR-506 suppresses liver cancer angiogenesis through targeting sphingosine kinase 1 (SPHK1) mRNA. Biochemical and biophysical research communications. 2015; 468(1-2):8-13.

57. Zhang M, Xu Q, Yan S, Li Z, Yan W and Jia X. Suppression of forkhead box Q1 by microRNA-506 represses the proliferation and epithelial-mesenchymal transition of cervical cancer cells. Oncology reports. 2016; 35(5):31063114 .

58. Creighton C, Zhou L, Chen J, Li Z, Li X, Hu X, Huang Y, Zhao X, Liang C, Wang Y, Sun L, Shi M, Xu X, Shen F, Chen M, Han Z, et al. Integrated Profiling of MicroRNAs and mRNAs: MicroRNAs Located on Xq27.3 Associate with Clear Cell Renal Cell Carcinoma. PloS one. 2010; 5(12):e15224.

59. Yu Z, Zhang Y, Gao N and Wang X. Overexpression of miR-506 inhibits growth of osteosarcoma through Snail2. American journal of translational research. 2015; 7(12):2716-2723.

60. Luo Y, Sun R, Zhang J, Sun T, Liu X and Yang B. miR-506 inhibits the proliferation and invasion by targeting IGF2BP1 in glioblastoma. American journal of translational research. 2015; 7(10):2007-2014.

61. Yin M, Ren X, Zhang X, Luo Y, Wang G, Huang K, Feng S, Bao X, Huang K, He X, Liang P, Wang Z, Tang H, He $\mathrm{J}$ and Zhang B. Selective killing of lung cancer cells by miRNA-506 molecule through inhibiting NF-(kappa)B p65 to evoke reactive oxygen species generation and p53 activation. Oncogene. 2014; 34(6):691-703.

62. An F, Zhang Z, Xia M and Xing L. Subpath analysis of each subtype of head and neck cancer based on the regulatory relationship between miRNAs and biological pathways. 
Oncology reports. 2015; 34(4):1745-1754.

63. Li J, Xu YH, Lu Y, Ma XP, Chen P, Luo SW, Jia ZG, Liu Y and Guo Y. Identifying differentially expressed genes and small molecule drugs for prostate cancer by a bioinformatics strategy. Asian Pacific journal of cancer prevention. 2013; 14(9):5281-5286.

64. Zhao Z, Ma X, Hsiao TH, Lin G, Kosti A, Yu X, Suresh U, Chen Y, Tomlinson GE, Pertsemlidis A and Du L. A highcontent morphological screen identifies novel microRNAs that regulate neuroblastoma cell differentiation. Oncotarget. 2014; 5(9):2499-2512. doi: 10.18632/oncotarget.1703.

65. Iorio MV and Croce CM. Causes and consequences of microRNA dysregulation. Cancer journal. 2012; 18(3):215222.

66. Lujambio A, Ropero S, Ballestar E, Fraga MF, Cerrato C, Setien F, Casado S, Suarez-Gauthier A, Sanchez-Cespedes M, Git A, Spiteri I, Das PP, Caldas C, Miska E and Esteller $\mathrm{M}$. Genetic unmasking of an epigenetically silenced microRNA in human cancer cells. Cancer research. 2007; 67(4):1424-1429.

67. Lopez-Serra P and Esteller M. DNA methylation-associated silencing of tumor-suppressor microRNAs in cancer. Oncogene. 2012; 31(13):1609-1622.
68. Zhao M, Sun JC and Zhao ZM. Synergetic regulatory networks mediated by oncogene-driven microRNAs and transcription factors in serous ovarian cancer. Mol Biosyst. 2013; 9(12):3187-3198.

69. Bouchie A. First microRNA mimic enters clinic. Nature biotechnology. 2013; 31(7):577.

70. Kong YW, Ferland-McCollough D, Jackson TJ and Bushell M. microRNAs in cancer management. The Lancet Oncology. 2012; 13(6):e249-258.

71. Thorsen SB, Obad S, Jensen NF, Stenvang J and Kauppinen $\mathrm{S}$. The therapeutic potential of microRNAs in cancer. Cancer journal. 2012; 18(3):275-284.

72. Xu G and Li JY. Differential expression of PDGFRB and EGFR in microvascular proliferation in glioblastoma. Tumour biology. 2016.

73. Markova SM and Kroetz DL. ABCC4 is regulated by microRNA-124a and microRNA-506. Biochem Pharmacol. 2014; 87(3):515-522. 